\title{
Treatment of Schatzker Type II-VI Tibial Plateau Fractures by Means of Syndesmotaxis Using an Ilizarov External Fixator and Postoperative CT Evaluation
}

Stamatios A. Papadakis ${ }^{1}$, Dimitrios Pallis ${ }^{1}$, Margarita-Michaela Ampadiotaki ${ }^{1}$, Georgios Gourtzelidis ${ }^{1}$, Konstantinos Kateros ${ }^{2}$, George Macheras ${ }^{3}$

1. B' Orthopaedic Department, KAT General Hospital of Attica, Athens, GRC 2. A' Orthopaedic Department, General Hospital G.Gennimatas, Athens, GRC 3. D' Orthopaedic Department, KAT General Hospital of Attica, Athens, GRC

Corresponding author: Margarita-Michaela Ampadiotaki, marab.ortho@gmail.com

\section{Abstract \\ Introduction}

Tibial plateau fractures are more common in young patients following high-energy trauma. In this study, we aim to evaluate the articular surface reduction quality by means of postoperative computer tomography (CT) in Schatzker type II-VI tibial plateau fractures treated with an Ilizarov frame.

\section{Materials and methods}

This case series study included 45 patients with a mean age of 39.5 years (range: 18 to 65 years) with a Schatzker type II-VI tibial plateau fracture. The surgical technique was a mini-open reduction of the articular surface impaction followed by application of an Ilizarov circular frame with knee bridging. Pre- and postoperative CT scan evaluation was performed in all of the patients. Outcomes were measured using the American Knee Society Score (AKSS). Mean outpatient follow-up was of at least 12 months (range: 12 to 21 months). Mean time for fracture consolidation was 15.5 weeks (range: 13 to 19 weeks). According to the degree of postoperative articular surface impaction, patients were grouped as follows: 11 had less than $2 \mathrm{~mm}$ of depression, 27 had 2 to $4 \mathrm{~mm}$ of depression, and 7 over $4 \mathrm{~mm}$ of depression.

\section{Results}

Patients with articular surface impaction of more than $4 \mathrm{~mm}$ presented statistically significant lower values of AKSS compared to those with impaction of lower than $2 \mathrm{~mm}(\mathrm{p}<0.001)$ and $2-4 \mathrm{~mm}(\mathrm{p}<0.001)$. Patients with joint alignment equal to or more than $5^{\circ}$ presented statistically significant lower values of AKSS compared to those with lower than $5^{\circ}$.

Review began 12/28/2020 Review ended 01/08/2021 Published 01/13/2021

\section{(๑) Copyright 2021}

Papadakis et al. This is an open access article distributed under the terms of the Creative Commons Attribution License CC-BY 4.0., which permits unrestricted use, distribution, and reproduction in any medium, provided the original author and source are credited.

\section{Conclusions}

Schatzker type II-VI tibial plateau fractures may be treated successfully with mini-open reduction and the application of an Ilizarov frame. The increase of articular surface impaction by $1 \mathrm{~mm}$ causes reduction of AKSS by 15 units. Patients with joint alignment equal to or more than $5^{\circ}$ present lower values of AKSS. The preoperative CT scan is important and useful in planning the surgical intervention no matter the classification system is used.

Categories: Orthopedics, Trauma

Keywords: tibial plateau fractures, ilizarov fixator, computed tomography

\section{Introduction}

Tibial plateau fractures are more common in young patients following high-energy trauma. These fractures in the elderly with osteoporotic bone are caused by low-energy fall. Fractures of tibial plateau are caused by direct axial compression combined with a varus or valgus force. These fractures are usually associated with soft tissue injuries. The severity of soft tissue injuries should be evaluated properly and not be underestimated. Associated vascular injuries and compartment syndrome are not uncommon in complex tibial plateau fractures [1].

The anatomy of the tibial plateau is complex and should be keeping in mind during the reduction. The shape of the tibial plateau is asymmetric and has a direct role in the biomechanics of the tibiofemoral joint. The position of the knee at impact and the characteristics of the force such as the direction and the magnitude determine the injury pattern and the damage of soft tissue envelope [2]. 
Injury pattern, articular surface impaction, soft tissue condition, condylar dissociation, and extension of fracture line in metaphysis should be considered prior to the treatment method [2]. Ilizarov external fixator provides adequate stabilization of these fractures and restores the articular surface and the mechanical axis without compromising the condition of the soft tissue envelope. Restoration of articular surface and of mechanical axis correlates most with a satisfactory clinical outcome [3].

\section{Materials And Methods}

This prospective case series study included 45 patients, with a mean age of 39.5 years (range: 18 to 65 years), and the fracture types were classified according to the Schatzker classification [4]. Inclusion criteria were the presence of complex Schatzker type II-VI intra-articular proximal tibia fractures, patient age over 18 years, and the ability to walk without assistance before injury. Patients with bilateral tibial plateau fracture, those with an associated ipsilateral femoral fracture, and those lost to follow-up were excluded from the study. The study was approved by the Scientific Committee of our institution. The majority of cases were of closed injuries, except two cases (Gustilo-Anderson type 3a and type 2). In all of the cases, prophylactic antibiotics were administered intravenously according to protocol. Two patients with open fractures were treated with debridement and irrigation (Table 1). Closed fractures were operated with an average of four days' delay (range: 3 to 7 days) in order to allow amelioration of soft tissue damage. Pre- and postoperatively, a CT scan of the injured knee was performed in order to evaluate the fracture pattern, the reduction of the articular surface, and the restoration of the mechanical axis. Follow-up duration ranged from 12 to 21 months. Outcome was measured using the American Knee Society Score (AKSS) at the 12 months' assessment.

\begin{tabular}{|c|c|c|c|c|c|c|c|}
\hline $\begin{array}{l}\text { Case } \\
\text { Number }\end{array}$ & Age & $\begin{array}{l}\text { Schatzker } \\
\text { type }\end{array}$ & $\begin{array}{l}\text { Open } \\
\text { fracture }\end{array}$ & $\begin{array}{l}\text { Preoperative step } \\
(\mathrm{mm})\end{array}$ & $\begin{array}{l}\text { Joint alignment } \\
\left(0^{\circ}\right)\end{array}$ & $\begin{array}{l}\text { Articular surface impaction } \\
(\mathrm{mm})\end{array}$ & $\begin{array}{l}\text { AKSS } \\
\text { total }\end{array}$ \\
\hline 1 & 18 & VI & No & 28 & 4 Varus & $<2$ & 191 \\
\hline 2 & 22 & V & No & 13 & 9 Varus & 3 & 182 \\
\hline 3 & 29 & VI & No & 16 & 12 Valgus & 4 & 141 \\
\hline 4 & 23 & VI & No & 9 & 7 Valgus & 2 & 169 \\
\hline 5 & 39 & V & No & 11 & 5 Varus & 4 & 149 \\
\hline 6 & 36 & V & No & 14 & 3 Valgus & 2 & 183 \\
\hline 7 & 32 & VI & $\begin{array}{l}\text { Gustilo type } \\
\text { IIIA }\end{array}$ & 11 & 7 varus & 5 & 147 \\
\hline 8 & 45 & III & No & 12 & 7 Varus & 3 & 180 \\
\hline 9 & 55 & II & No & 10 & 3 Varus & 3 & 171 \\
\hline 10 & 36 & V & No & 9 & 4 Varus & 3 & 184 \\
\hline 11 & 37 & V & No & 7 & 3 Varus & $<2$ & 184 \\
\hline 12 & 51 & VI & No & 19 & 3 Valgus & 5 & 126 \\
\hline 13 & 24 & VI & No & 33 & 3 Valgus & 4 & 180 \\
\hline 14 & 45 & V & $\begin{array}{l}\text { Gustilo type } \\
\text { II }\end{array}$ & 12 & 9 Varus & 5 & 129 \\
\hline 15 & 42 & VI & No & 17 & 3 Varus & 5 & 123 \\
\hline 16 & 48 & VI & No & 13 & 4 Varus & 6 & 119 \\
\hline 17 & 51 & VI & No & 11 & 2 Valgus & $<2$ & 183 \\
\hline 18 & 33 & V & No & 9 & 2 Varus & $<2$ & 190 \\
\hline 19 & 42 & VI & No & 15 & 8 Valgus & 6 & 119 \\
\hline 20 & 44 & V & No & 9 & 4 Varus & 3 & 171 \\
\hline 21 & 46 & II & No & 7 & 2 Varus & $<2$ & 184 \\
\hline 22 & 36 & V & No & 8 & 2 Varus & 2 & 172 \\
\hline 23 & 39 & VI & No & 7 & 2 Varus & $<2$ & 177 \\
\hline 24 & 35 & VI & No & 13 & 5 Valgus & 5 & 126 \\
\hline
\end{tabular}




\section{Cureus}

\begin{tabular}{|c|c|c|c|c|c|c|c|}
\hline 25 & 47 & V & No & 9 & 2 Varus & $<2$ & 177 \\
\hline 26 & 41 & V & No & 14 & 2 Varus & 2 & 172 \\
\hline 27 & 29 & V & No & 9 & 3 Varus & 3 & 164 \\
\hline 28 & 43 & v & No & 11 & 3 Varus & 3 & 170 \\
\hline 29 & 36 & V & No & 13 & 2 Varus & 3 & 166 \\
\hline 30 & 28 & V & No & 8 & 5 Varus & $<2$ & 185 \\
\hline 31 & 36 & V & No & 9 & 2 Valgus & $<2$ & 192 \\
\hline 32 & 43 & VI & No & 12 & 4 Varus & 4 & 164 \\
\hline 33 & 39 & V & No & 9 & 7 Varus & 3 & 160 \\
\hline 34 & 57 & V & No & 8 & 4 Valgus & 3 & 172 \\
\hline 35 & 19 & VI & No & 11 & 3 Varus & $<2$ & 192 \\
\hline 36 & 33 & V & No & 9 & 2 Varus & 3 & 177 \\
\hline 37 & 34 & V & No & 7 & 4 Varus & 3 & 176 \\
\hline 38 & 37 & V & No & 12 & 2 Varus & 4 & 156 \\
\hline 39 & 50 & V & No & 9 & 5 Varus & 3 & 164 \\
\hline 40 & 49 & V & No & 9 & 3 Varus & $<2$ & 185 \\
\hline 41 & 65 & VI & No & 8 & 5 Varus & 2 & 171 \\
\hline 42 & 36 & v & No & 15 & 3 Varus & 3 & 170 \\
\hline 43 & 47 & VI & No & 9 & 2 Valgus & 3 & 184 \\
\hline 44 & 59 & III & No & 8 & 2 Varus & 2 & 177 \\
\hline 45 & 43 & $\|$ & No & 11 & 3 Valgus & 3 & 176 \\
\hline
\end{tabular}

\section{Surgical technique}

All patients were positioned supine on a traction table with the knee extended to assist in the reduction (Figure 1 a). A traction table contributes $360^{\circ}$ visualization using an image intensifier and allows the use of a circular ring fixator without impingement on the table [5]. The reduction is achieved through ligamentotaxis. Ligaments can transfer load from bone to bone, lengthwise the axis that they are acting [6]. The soft tissue envelope transfers load to the bony fragments, and through traction, alignment of the joint is achieved by indirect reduction (Table 2).

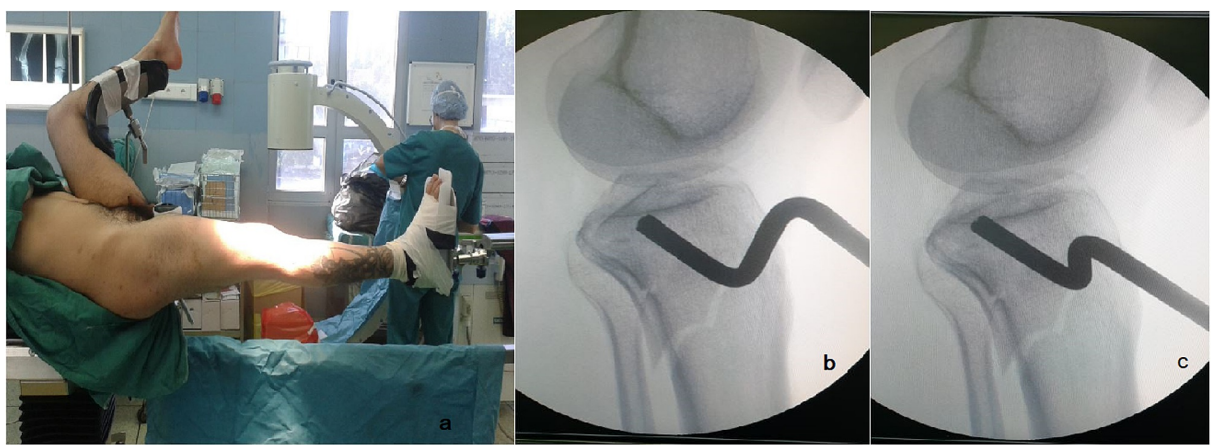

FIGURE 1: (a) Photo of the patient position on the traction table. (b, c) Intraoperative fluoroscopy images showing a depression of the articular surface and its reduction using an elevator. 


\begin{tabular}{|l|l|l|}
\hline Structures & Tight in flexion & Tight In extension \\
\hline Anterior cruciate ligament & Anteromedial bundle & Anterolateral bundle \\
Posterior cruciate ligament & Posterolateral bundle & Posteromedial bundle \\
Lateral collateral ligament & Lax in flexion & Tight in extension \\
Medial collateral ligament & - & Tight in extension and valgus \\
Quadriceps femoris muscle & Tight in flexion & - \\
\hline Semitendinosus muscle & - & Tight in extension and external rotation \\
\hline Semimembranosus muscle & - & Tight in extension and external rotation \\
Sartorius muscle & - & Tight in extension and external rotation \\
Popliteus muscle & - & Tight in extension and external rotation \\
Iliotibial band & - & Tight in extension and internal rotation \\
Gastrocnemius muscle & - & Tight in extension \\
\hline Biceps femoris muscle & - & Tight in extension and internal rotation \\
Gracilis muscle & - & Tight in extension and external rotation \\
Articular capsule & & Tight in extension \\
\hline
\end{tabular}

TABLE 2: Structures around the knee and their action.

$[7]$

In this way, bony fragments attached to the soft tissue are positioned back in place. Furthermore, the joint capsule and the attachment of muscles and tendons masses surrounding the knee joint could put pressure on bony fragments and thus contribute to the reduction. The intensity of the traction for the reduction of the articular alignment is controlled through fluoroscopic imaging. However, impacted articular fragments remain unreduced. In these cases with inadequate reduction, a 1.5- to 3-cm incision is performed over the anterolateral aspect of the tibial metaphysis. Through this opening, an elevator is used under fluoroscopy for the elevation and reduction of the articular surface (Figures $1 \mathrm{~b}, 1 \mathrm{c}$ ). Allografts are used in order to fill the remaining osseous gap. Two cannulated screws are inserted below the articular surface in order to restore and maintain the reduction, the joint expansion, and the position of the allografts. An Ilizarov frame bridging the knee is placed under traction. Bridging is used to preserve the reduction and to maintain the joint extension and stability. The proximal tibial wires are positioned at least $1 \mathrm{~cm}$ below the articular surface, avoiding a possible septic arthritis due to pin track infection [7]. Knee bridging was applied in all of the cases and lasts up to six weeks.

We do not use arthroscopy to evaluate the articular reduction as we believe that the pressure of the arthroscopy fluids may lead to misalignment or displacement of the articular bony fragments. Also, there may be a risk factor of compartment syndrome that could compromise negatively the soft tissue envelope.

\section{Statistical analysis}

Data were expressed as means for quantitative variables and as percentages for categorical variables. The Kolmogorov-Smirnov test was utilized for normality analysis of the quantitative variables. Correlation between functional variables was examined using Spearman's correlation coefficient.

Comparisons between different categories of qualitative variables in relation to AKSS score were performed using the independent samples t-test and one-way analysis of variance model (pairwise comparisons examined using Bonferroni correction).

All variables whether or not they demonstrated significant associations with outcome in unifactorial analysis were included in the multiple linear regression models, and the enter method was used to explore the independent predictors of AKSS score.

All assumptions of linear regression analysis (homoscedasticity, linearity, normality, and independence of 


\section{Cureus}

error terms, as well as multicollinearity of independent variables) were examined.

All tests were two-sided, and the statistical significance was set at $\mathrm{p}<0.05$. All analyses were carried out using SPSS Version 21.00 (IBM Corporation, Armonk, NY, USA).

\section{Results}

All fractures healed, and the mean time for fracture consolidation was 15.5 weeks (range: 13 to 19 weeks). According to postoperative CT scan and degree of postoperative articular surface impaction, patients were grouped as follows: 11 (24.4\%) had less than $2 \mathrm{~mm}$ of impaction, 27 (60\%) had 2 to $4 \mathrm{~mm}$ of impaction, and 7 $(15,5 \%)$ over $4 \mathrm{~mm}$ of impaction. The AKSS was good or excellent in 21 patients and poor or fair in 10 patients. The AKSS function score was good or excellent in 29 patients and poor or fair in 16 (Table 3).

\begin{tabular}{|c|c|c|c|c|c|c|c|}
\hline \multicolumn{4}{|c|}{ AKSS knee score category } & \multicolumn{4}{|c|}{ AKSS function score category } \\
\hline Poor $(<60)$ & Fair (60-69) & Good (70-79) & Excellent $(80-100)$ & Poor $(<60)$ & Fair (60-69) & Good (70-79) & Excellent $(80-100)$ \\
\hline 3 & 7 & 14 & 21 & 5 & 11 & 8 & 21 \\
\hline $6.6 \%$ & $15.5 \%$ & $31.1 \%$ & $46.6 \%$ & $11.1 \%$ & $24.4 \%$ & $17.7 \%$ & $46.6 \%$ \\
\hline
\end{tabular}

TABLE 3: Patients knee scores

AKSS, American Knee Society Score

Preoperative step $(\mathrm{p}=0.018)$ and joint alignment $(\mathrm{p}=0.004)$ were moderate and negatively correlated with AKSS, and articular surface impaction $(\mathrm{p}<0.001)$ was high and negatively correlated with AKSS (Table 4).

\section{Characteristics}

Age

Schatzker type II/III/V/VI, n (\%)

Open fracture, no/yes, n (\%)

Preoperative articular impaction (mm), mean (min-max)

Joint alignment (grade), mean (range)

Joint alignment (type), varus/valgus, n (\%)

Joint alignment (grade), $<5 / \geq 5$

Articular surface impaction (mm), mean (range)

Articular surface impaction (mm), <2/2-4/>4, n (\%)

AKSS, mean (range)
39.5 ( 18-65)

$5(11.1) / 24(53.3) / 16(5.6)$

$43(95.6) / 2(4.4)$

$11.6(7-33)$

$4.0(2-12)$

33 (73.3)/12 (26.7)

$32(71.1) / 13$ (28.9)

$3.1(2-6)$

$11(24.4) / 27(60.0) / 7$ (15.6)

166.4 (119-192)

\section{TABLE 4: Demographic and clinical characteristics}

Preoperative step $(r=-0,352 ; p=0.018)$ and joint alignment $(r=-0,422 ; p=0.004)$ were moderate and negatively correlated with AKSS score, and articular surface impaction $(r=-0,892 ; p<0.001)$ was very high and negatively correlated with AKSS score.

AKSS, American Knee Society Score

A multiple regression model with the enter method was employed to examine the contribution of demographic and functional variables to AKSS score. Only the amount of articular surface impaction $(\mathrm{p}<0.001)$ was a statistically significant prognostic factor of AKSS score (Table 5). 


\section{Cureus}

\begin{tabular}{|c|c|c|c|c|c|}
\hline & Reference category & $\mathbf{R}^{2}$ & Beta & SE & p-Value \\
\hline Age & --- & $<0.01$ & -0.23 & 0.16 & 0.149 \\
\hline Schatzker type & II-III-V & $<0.01$ & -4.47 & 3.57 & 0.218 \\
\hline Preoperative step (mm) & --- & $<0.01$ & 0.21 & 0.38 & 0.588 \\
\hline Joint alignment (grade) & --- & 0.01 & -0.78 & 0.71 & 0.278 \\
\hline Joint alignment (valgus) & Varus & $<0.01$ & 2.33 & 3.52 & 0.512 \\
\hline Articular surface impaction (mm) & $\cdots$ & 0.80 & -14.96 & 1.65 & $<0.001$ \\
\hline
\end{tabular}

\section{TABLE 5: Multifactorial linear regression of AKSS score}

The amount of articular surface impaction (beta coefficient \pm SE: $-14.96 \pm 1.65 ; R 2=80 \% ; p<0.001$ ) was a statistically significant prognostic factor of AKSS score. Based on the very high value of $R^{2}$ of articular surface impaction variable in the multiple linear regression models, we can assume that the articular surface impaction is the most important factor that affects the functional status of a patient.

SE, standard error; AKSS, American Knee Society Score

Patients with Schatzker type VI presented statistically significant lower values of AKSS score compared to those with type II-IV ( $\mathrm{p}=0.009)$ and type $\mathrm{V}(\mathrm{p}<0.05)$. Patients with articular surface impaction of more than 4 $\mathrm{mm}$ presented statistically significant lower values of AKSS compared to those with impaction of lower than $2 \mathrm{~mm}(\mathrm{p}<0.001)$ and $2-4 \mathrm{~mm}(\mathrm{p}<0.001)$ (Table 6$)$.

\begin{tabular}{|c|c|c|c|c|}
\hline & & $\mathbf{n}$ & AKSS score & $\mathrm{p}$-Value \\
\hline \multirow{3}{*}{ Schatzker type } & II-III & 5 & $177.6 \pm 4.8^{\mathrm{a}}$ & \multirow{3}{*}{0.008} \\
\hline & V & 24 & $172.0 \pm 14.1^{b}$ & \\
\hline & VI & 16 & $154.4 \pm 26.1$ & \\
\hline \multirow{2}{*}{ Joint alignment (type) } & Varus & 33 & $167.8 \pm 18.2$ & \multirow{2}{*}{0.541} \\
\hline & Valgus & 12 & $162.6 \pm 26.6$ & \\
\hline \multirow{2}{*}{ Joint alignment ( grade) } & $<5$ & 32 & $170.8 \pm 18.5$ & \multirow[b]{2}{*}{0.022} \\
\hline & $\geq 5$ & 13 & $155.5 \pm 22.2$ & \\
\hline \multirow{3}{*}{ Articular surface impaction $(\mathrm{mm})$} & $<2$ & 11 & $184.7 \pm 5.1^{\mathrm{c}, \mathrm{d}}$ & \multirow{3}{*}{$<0.001$} \\
\hline & $2-4$ & 27 & $169.1 \pm 10.8^{c}$ & \\
\hline & $>4$ & 7 & $127.0 \pm 9.6$ & \\
\hline
\end{tabular}

\section{TABLE 6: Correlation between AKSS and qualitative functional variables}

Patients with Schatzker type VI presented statistically significant lower values of AKSS compared to type II-IV $(p=0.009)$ and type V $(p=0.054)$. Patients with joint alignment equal to or more than $5^{\circ}$ presented statistically significant lower values of AKSS compared to those with lower than $5^{\circ}$ $(p=0.022)$. Patients with articular surface impaction of more than $4 \mathrm{~mm}$ presented statistically significant lower values of AKSS compared to those with lower than $2 \mathrm{~mm}(p<0.001)$ and $2-4 \mathrm{~mm}(p<0.001)$.

${ }^{a} p=0.009$ vs. VI; ${ }^{b} p=0.054$ vs. VI; ${ }^{c} p<0.001$ vs. $>4 ;{ }^{d} p<0.001$ vs. II-IV

AKSS, American Knee Society Score

Furthermore, patients with joint alignment equal to or more than $5^{\circ}$ presented statistically significant lower values of AKSS compared to those with lower than $5^{\circ}(\mathrm{p}=0.022)$ (Table 6$)$. All fractures healed, and there were no complications such as deep venous thrombosis, malunion, non-union (septic or no), osteomyelitis, and systemic complications (Figure 2). 


\section{Cureus}
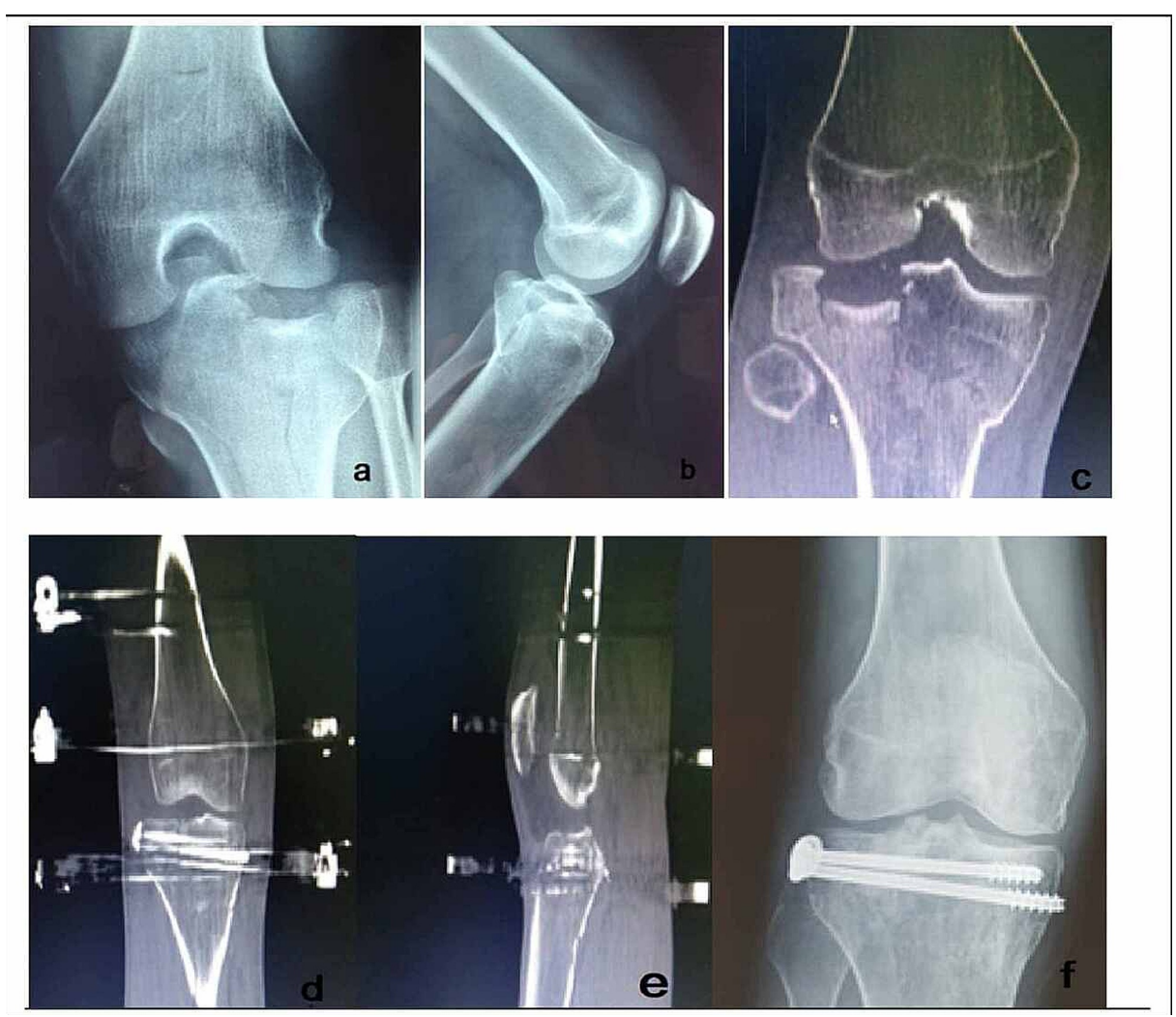

FIGURE 2: An 18-year-old man with a displaced bicondylar tibial plateau fracture.

(a, b) Anteroposterior and lateral preoperative X-ray (c) Preoperative axial CT scan of the knee joint. (d) Postoperative CT scan (axial view) following mini-open reduction of the articular surface and application of an llizarov frame with knee bridging. (e) Postoperative sagittal CT scan view of the same patient. (f) Anteroposterior X-ray 5 months postoperatively.

Only one patient presented with pin track infection and was treated with local pin care and oral antibiotics without requiring removal of wires or half pins. Three patients presented with decreased range of knee motion due to stiffness and were treated with mobilization under anesthesia. Ilizarov external fixator was discharged after an average time of 4.4 months (range: 4 to 6 months) (Figure 3). 


\section{Cureus}
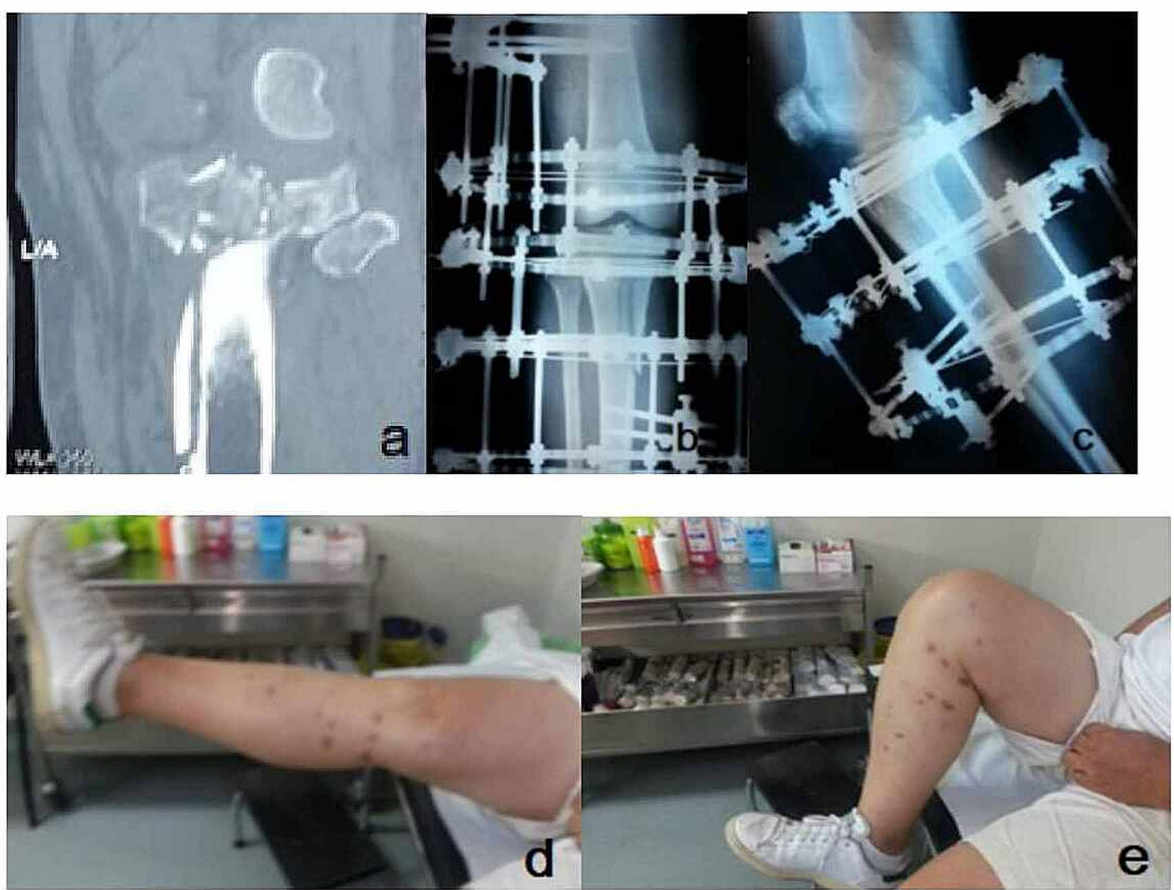

\section{FIGURE 3: A 65-year-old man with a Schatzker type VI tibial plateau fracture}

(a) Axial CT scan view of the fracture. (b) An anteroposterior intraoperative radiograph following mini-open reduction of the articular surface and application of an llizarov frame with knee bridging. (c) Lateral view of the knee joint after the removal of the knee bridging. (d, e) Range of motion in extension and flexion six months postoperatively in the same patient.

\section{Discussion}

Complex tibial fractures are usually associated with knee stiffness and walking impairments [8]. Although there are more than 32 different classification systems, the Schatzker, AO/OTA, and recently the Luo threecolumn classification systems are vastly utilized [9]. In our opinion, no matter which classification is used, the preoperative CT scan is of great importance and the most useful tool for planning the surgical intervention.

Treatment modalities currently include closed reduction and casting, open reduction and internal fixation, limited internal fixation with external circular fixator, and a combination of an internal fixation with a hybrid external fixator [10]. The anatomical and clinical outcome seems to be equal in the treatment of tibial plateau fractures regardless of the treatment method [11]. There are studies suggesting that ring fixation system combined with minimal internal fixation provides better clinical outcome [10].

The external fixator as a definitive treatment for patients with complex tibial plateau has also been described [12]. Hall et al. stated that good clinical outcomes could be achieved in complex fractures treated by external fixator than open reduction internal fixator [13]. Ligamentotaxis is used for reduction [14]. It is a term used to emphasize that for traction to be effective, it must be balanced by counter traction provided by ligaments and soft tissue surrounding the bone. Bridging across the knee increases the stability of the fixation, reduces the forces on the articular surface, and lessens the incidence of loosening of reduction in severely comminuted fractures [13]. We prefer joint stability rather than the potential stiffness due to the duration of bridging. Furthermore, the potential knee stiffness that can be seen postoperatively can provide stability for the fracture healing process [10]. Up to $90 \%$ results with good or excellent range of motion and stability are reported in patients who treated with Ilizarov external fixator as definitive treatment in complex tibial plateau fractures [15]. Keightley et al. reported good long-term healing and functional outcomes in Schatzker type IV-VI tibial plateau fractures treated with an Ilizarov technique [16,17]. Debnath et al. recommended the Ilizarov technique for Schatkzer type VI tibial plateau fractures with comminution [18]. Reddy et al. reported good healing rates and low incidence of infection in Schatzker type II and above tibial plateau fractures [19]. In our study, we have also evaluated Schatzker type II-VI tibial plateau fracture and found similar results.

Stable open reduction internal fixation and early mobilization for these injuries is the gold standard, but there is a significant risk. The extended incision to gain access to both medial and lateral plateau causes 
further soft tissue damage, increases the risk of infection, and delays union. Poor outcomes are related with severe soft tissue injury [20]. There is a list of potential complications ranging from early wound problems to amputation in case of a severe infection [10,14,21]. McNamara et al. also stated that there is not enough evidence to ascertain the best method of fixation [22].

One of the treatment goals in complex tibial plateau is the preservation of the soft tissue envelope bearing in mind a potential future total knee arthroplasty. Bove et al. suggest that Ilizarov frame is more effective than open reduction and internal fixation in complex tibial plateau fractures due to low incidence of infection and early mobilization [23]. In our study, only one (0.02\%) patient had a pin track infection. Frames preserve the blood supply, protect the osteogenic factors, and permit early function of muscles, thus allowing early mobilization. They also allow potential change of fragment position in multiple planes with the fixator in place. Moreover, they permit fragments stabilization distally with the same device. Ringtensioned wire frames provide mechanical stability of the fracture comparable with dual-plating internal fixation [24]. Barbary et al. reported a low rate of morbidity and satisfactory clinical outcome with the combination of Ilizarov technique and minimal internal fixation in patients with Schatzker type VI tibial plateau fractures [25].

A residual varus or valgus deformity is common. This could be attributed either to initial malreduction or postoperative loss of reduction. Nevertheless, moderate deformity is compatible with satisfactory clinical outcome [26]. Maintenance of mechanical axis is one of the goals of treatment and correlates with excellent results in function and clinical outcome. In our study, patients with joint alignment equal to or more than $5^{\circ}$ presented statistically significant lower values of AKSS compared to those with lower than $5^{\circ}$. According to Rademakers et al., malalignment of the mechanical axis greater than $5^{\circ}$ of the controlateral limb tripled the incidence of degenerative osteoarthritis ( $27 \%$ vs. $9 \%$ ) at up to 27 years follow-up. Age at the time of injury had no effect on functional results [27].

There is a wide range of acceptable residual articular surface displacement ranging from 2 to $12 \mathrm{~mm}[26,28]$. According to our study results, the postoperative articular surface depression showed a statistically significant correlation with the AKSS. Patients with articular depression $>4 \mathrm{~mm}$ had poor or fair results, whereas patients with articular depression $<4 \mathrm{~mm}$ had good or excellent results. The increase of articular surface impaction by $1 \mathrm{~mm}$ causes reduction of AKSS by 15 units. Based on the very high value of R2 of articular surface impaction variable in the multiple linear regression model, we can assume that the collapsed joint is the most important factor that affects the functional status of a patient (Table 5). Our findings are in accordance with the recent study by Kateros et al., who reported that patients who were treated with hybrid external fixator and had residual joint depression of $>4.5 \mathrm{~mm}$ showed significant poor or fair results with the AKSS [29].

Giannoudis et al. stated that multiple factors, such as knee stability, varus or valgus malalignment, and preservation of the meniscus, have a significant role in the clinical outcome and risk of posttraumatic osteoarthritis than articular congruity. They also reported that the thicker cartilage of the tibial plateau in relation to other joints potentially reduces the risk of posttraumatic osteoarthritis compared with similar articular depression at other joints [30]. To our knowledge, there are a few studies evaluating the articular surface reduction by using fluoroscopy intraoperatively. There is no clear evidence about the specificity, sensitivity, and interobserver agreement in grading the articular surface step-off using fluoroscopy intraoperatively or X-rays postoperatively. Preoperative CT is more useful than X-rays for the classification and evaluation of tibial plateau fractures. Postoperative CT scan is important in determining the reduction of the articular surface and the healing process [30]. Unfortunately, this is performed when the patient has already left the operating theater.

\section{Conclusions}

Ilizarov external fixator with knee bridging and mini-open reduction as a definitive treatment option for Schatzker type II-VI tibial plateau fractures provides adequate stabilization and restores articular surface and mechanical axis without compromising the soft tissue envelope. The increase of articular surface impaction by $1 \mathrm{~mm}$ causes reduction of AKSS by 15 units. Patients with joint alignment equal to or more than $5^{\circ}$ present lower values of AKSS. The preoperative CT scan is of great importance and the most useful tool for planning surgical intervention no matter which classification system is used.

\section{Additional Information}

\section{Disclosures}

Human subjects: Consent was obtained or waived by all participants in this study. Animal subjects: All authors have confirmed that this study did not involve animal subjects or tissue. Conflicts of interest: In compliance with the ICMJE uniform disclosure form, all authors declare the following: Payment/services info: All authors have declared that no financial support was received from any organization for the submitted work. Financial relationships: All authors have declared that they have no financial relationships at present or within the previous three years with any organizations that might have an interest in the submitted work. Other relationships: All authors have declared that there are no other 
relationships or activities that could appear to have influenced the submitted work.

\section{References}

1. Lee JA, Papadakis SA, Moon C, Zalavras CG: Tibial plateau fractures treated with the less invasive stabilisation system. Int Orthop. 2007, 31:415-418. 10.1007/s00264-006-0176-X

2. Hashemi J, Chandrashekar N, Gill B, et al.: The geometry of the tibial plateau and its influence on the biomechanics of the tibiofemoral joint. J Bone Joint Surg Am. 2008, 90:2724-2734. 10.2106/JBJS.G.01358

3. Kumar A, Whittle AP: Treatment of complex (Schatzker type VI) fractures of the tibial plateau with circular wire external fixation: retrospective case review. J Orthop Trauma. 2000, 14:339-344. 10.1097/00005131200006000-00006

4. Schatzker J, McBroom R, Bruce D: The tibial plateau fracture. The Toronto experience 1968-1975 . Clin Orthop. 1979, 138:94-104.

5. Elgazzar AS, Mohamady EM, Kandil WA: Management of comminuted tibial plateau fractures with external fixator using ligamentotaxis principle. Egypt Orthop J. 2014, 49:167-173. 10.4103/1110-1148.145405

6. Woo SL, Abramowitch SD, Kilger R, Liang R: Biomechanics of knee ligaments: injury, healing, and repair . J Biomech. 2006, 39:1-20.

7. Whiteside LA: Ligament Balancing in Total Knee Arthroplasty: An Instructional Manual . Springer-Verlag, New York, NY; 2004.

8. Iliopoulos E, Agarwal S, Khaleel A: Walking impairments after severe tibia plateau fractures. A gait pattern analysis. J Orthop Sci. 2020, 25:276-278. 10.1016/j.jos.2019.03.015

9. Luo CF, Sun H, Zhang B, Zeng BF: Three-column fixation for complex tibial plateau fractures . J Orthop Trauma. 2010, 24:683-692. 10.1097/BOT.0b013e3181d436f3

10. Catagni MA, Ottavian G, Maggioni M: Treatment strategies for complex fractures of the tibial plateau with external circular fixation. J Trauma. 2007, 63:1043-1053. 10.1097/TA.0b013e3181238d88

11. Chan C, Keating J: Comparison of outcomes of operatively treated bicondylar tibial plateau fractures by external fixation and internal fixation. Malays Orthop J. 2012, 6:7-12. 10.5704/MOJ.1203.006

12. Watson JT, Coufal C: Treatment of complex lateral plateau fractures using Ilizarov techniques . Clin Orthop Relat Res. 1998, 353:97-106. 10.1097/00003086-199808000-00012

13. Hall JA, Beuerlein MJ, McKee MD; Canadian Orthopaedic Trauma Society: Open reduction and internal fixation compared with circular fixator application for bicondylar tibial plateau fractures. Surgical technique. J Bone Joint Surg Am. 2009, 91:74-88. 10.2106/JBJS.G.01165

14. Prat-Fabregat S, Camacho-Carrasco P: Treatment strategy for tibial plateau fractures: an update . EFORT Open Rev. 2016, 1:225-232. 10.1302/2058-5241.1.000031

15. Agee JM: External fixation. Technical advances based upon multiplaner ligamentotaxis . Orthop Clin North Am. 1993, 24:265-274.

16. Farooq U, Javed S, Ahmad I, Aziz A: Functional outcome of complex tibial plateau fractures managed with closed Ilizarov. J Pak Med Assoc. 2014, 64:104-107.

17. Keightley AJ, Nawaz SZ, Jacob JT, Unnithan A, Elliott DS, Khaleel A: Ilizarov management of Schatzker IV to VI fractures of the tibial plateau. Bone Joint J. 2015, 97:1693-1697. 10.1302/0301-620X.97B12.34635

18. Debnath UK, Jha DK, Pujari PK: Results of ring (Ilizarov) fixator in high energy Schatzker type VI fractures of proximal tibia. J Clin Orthop Trauma. 2018, 9:186-191. 10.1016/j.jcot.2017.08.005

19. Reddy RS, Kumar CY, Shah HM, Golla DK, Ganesh DJN, Kumar PA: Evaluation of tibial condyle fractures treated with Ilizarov fixation, a prospective study. J Clin Diagn Res. 2014, 11:5-7. 10.7860/JCDR/2014/9564.5117

20. Delamarter RB, Hohl M, Hopp E Jr: Ligament injuries associated with tibial plateau fractures . Clin Ortop Relat Res. 1990, 226:226-233.

21. Krettek C, Müller M, Miclau T: Evolution of minimally invasive plate osteosynthesis (MIPO) in the femur . Injury. 2001, 32:14-23. 10.1016/s0020-1383(01)00180-2

22. McNamara IR, Smith TO, Shepherd KL, Clark AB, Nielsen DM, Donell S, Hing CB: Surgical fixation methods for tibial plateau fractures. Cochrane Database Syst Rev. 2015, 2015:CD009679. 10.1002/14651858.CD009679.pub2

23. Bove F, Sala F, Capitani P, Thabet AM, Scita V, Spagnolo R: Treatment of fractures of the tibial plateau (Schatzker VI) with external fixators versus plate osteosynthesis. Injury. 2018, 49:12-18. 10.1016/i.injury.2018.09.059

24. Watson JT, Ripple S, Hoshaw SJ, Fhyrie D: Hybrid external fixation for tibial plateau fractures: clinical and biomechanical correlation. Orthop Clin North Am. 2002, 33:199-209. 10.1016/s0030-5898(03)00080-4

25. El Barbary H, Abdel Ghani H, Misbah H, Salem K: Complex tibial plateau fractures treated with Ilizarov external fixator with or without minimal internal fixation. Int Orthop. 2005, 29:182-185. 10.1007/s00264005-0638-6

26. Duwelius PJ, Connolly JF: Closed reduction of tibial plateau fractures. A comparison of functional and roentgenographic end results. Clin Orthop Relat Res. 1988, 230:116-126.

27. Rademakers MV, Kerkhoffs GM, Sierevelt IN, Raaymakers EL, Marti RK: Operative treatment of 109 tibial plateau fractures: five- to 27-year follow-up results. J Orthop Trauma. 2007, 21:5-10. 10.1097/BOT.0b013e31802c5b51

28. Weigel DP, Marsh JL: High-energy fractures of the tibial plateau: knee function after longer follow-up . J Bone Joint Surg Am. 2002, 84:1541-1551. 10.2106/00004623-200209000-00006

29. Kateros K, Galanakos SP, Kyriakopoulos G, Papadakis SA, Macheras GA: Complex tibial plateau fractures treated by hybrid external fixation system: a correlation of follow up computed tomography derived quality of reduction with clinical results. Indian J Orthop. 2018, 52:161-169.

30. Giannoudis PV, Tzioupis C, Papathanassopoulos A, Obakponovwe O, Roberts C: Articular step-off and risk of post-traumatic osteoarthritis. Evidence today. Injury. 2010, 41:986-995. 10.1016/j.injury.2010.08.003 